\title{
Stage IVB Pharyngeal Cancer
}

National Cancer Institute

\section{Source}

National Cancer Institute. Stage IVB Pharyngeal Cancer. NCI Thesaurus. Code C6001.

Stage IVB carcinoma of the pharynx according to the American Joint Committee on Cancer, 6th, 7th, and 8th editions. 